\title{
New estimation methods of Covid-19 cases and reproduction number with using a dynamic linear model and adaptive Kalman filter for the USA : New York, Arizona, Texas and Florida utilizing data between Marc and July 28th, 2020
}

levent $\ddot{o z b e k}^{1}$

${ }^{1}$ Ankara University

August 20, 2020

\begin{abstract}
In this study, cumulative and daily cases are estimated online using a discrete-time dynamic linear model (DLM) and Adaptive Kalman Filter (AKF) based on the total COVID-19 cases between Marc h-July 28, 2020 in USA-Florida, USA-Texas, USAArizona, USA-New York. Employing the data collected between Marc and July 28, 2020, it is showed that the discrete-time DLM in conjunction with AKF provides a good analysis tool for modeling the daily cases made using the in terms of mean square error (MSE) and. After estimating the number of cumulative cases, the daily case number estimate was calculated. After calculating the daily case number estimate, the reproduction number estimate was obtained. The method is online. Only the data on the last day is sufficient. The AKF has never been considered for such an application. To the best of our knowledge, the estimation of COVID-19 has not been studied with this method.
\end{abstract}

\section{Hosted file}

New estimation methods of Covid-19 cases and reproduction number.pdf available at https: //authorea.com/users/352590/articles/476758-new-estimation-methods-of-covid-19-casesand-reproduction-number-with-using-a-dynamic-linear-model-and-adaptive-kalman-filterfor-the-usa-new-york-arizona-texas-and-florida-utilizing-data-between-marc-and-july28 th -2020 